\title{
Effect of Cooked White Rice with High $\beta$-glucan Barley on Appetite and Energy Intake in Healthy Japanese Subjects: A Randomized Controlled Trial
}

\author{
Seiichiro Aoe • Takeshi Ikenaga • Hiroki Noguchi • \\ Chieko Kohashi $\cdot$ Keiji Kakumoto $•$ Noriyuki Kohda
}

Published online: 20 August 2014

(C) Springer Science+Business Media New York 2014

\begin{abstract}
White rice is a dominant grain-based food in Japan, but excess intake of polished rice may cause obesity. Barley is a grain-based food, similar to white rice, but it has the potential to control appetite and reduce energy intake. We investigated the effect of cooked white rice with high $\beta$-glucan barley on appetite and energy intake. The study was conducted as a randomized crossover design with twenty-one healthy Japanese women [mean \pm standard deviation body mass index (BMI) $\left.23.3 \pm 0.7 \mathrm{~kg} / \mathrm{m}^{2}\right]$. Subjects consumed a breakfast of cooked white rice with high $\beta$-glucan barley (BAR) or white rice (WR), followed by an ad libitum lunch and dinner. Energy intake was measured at the lunch and the dinner using plate waste. Subjects' perception scores on hunger, fullness, satiety, and prospective food consumption were assessed using a visual analogue scale (VAS) before and after the breakfast, lunch and dinner. BAR significantly reduced the VAS scores of hunger and prospective food consumption, and increased fullness before lunch compared to WR $(P=0.032,0.019$ and 0.038 , respectively). Energy intake at lunch and the cumulative energy intake (lunch + dinner) subsequent to BAR consumption were significantly lower than WR $(P=0.035$ and 0.021 , respectively). BAR was able to modulate appetite and
\end{abstract}

\section{S. Aoe}

Department of Food Science, Faculty of Home Economics, Otsuma Women's University, 12 Sanban-cho Chiyoda-ku, Tokyo 102-8357, Japan

T. Ikenaga $\cdot$ H. Noguchi $\cdot$ C. Kohashi $\cdot$ N. Kohda $(\bowtie)$ Otsu Nutraceuticals Research Institute, Nutraceuticals Division, Otsuka Pharmaceutical Co., Ltd., 3-31-13 Saigawa, Otsu, Shiga 520-0002, Japan

e-mail: Kohda.Noriyuki@otsuka.jp

\section{K. Kakumoto}

Tokushima Research Institute, Pharmaceuticals Division, Otsuka Pharmaceutical Co., Ltd., 463-10 Kagasuno, Kawauchi-cho, Tokushima 771-0192, Japan reduce energy intake. The combination of white rice with high $\beta$-glucan barley could play a beneficial role in preventing and treating obesity and other obesity-related metabolic diseases.

Keywords Barley $\cdot \beta$-glucan $\cdot$ Fibre $\cdot$ Appetite $\cdot$ Energy intake $\cdot$ Obesity

$\begin{array}{ll}\text { Abbreviations } \\ \text { ANOVA } & \text { Analysis of variance } \\ \text { BAR } & \text { Cooked white rice with high } \beta \text {-glucan barley } \\ \text { BMI } & \text { Body mass index } \\ \text { EAT } & \text { Eating attitudes test } \\ \text { GLP-1 } & \text { Glucagon-like peptide-1 } \\ \text { PYY } & \text { Peptide YY } \\ \text { SD } & \text { Standard deviation } \\ \text { VAS } & \text { Visual analogue scale } \\ \text { WR } & \text { White rice }\end{array}$

\section{Introduction}

The prevalence of being overweight or obese is increasing at an alarming rate in developed and developing countries throughout the world and epidemiological studies indicate that these are important risk factors for diabetes, cardiovascular disease, cancer and premature death [1].

Japanese and other Asian food, combining white rice (staple food) with side dishes, are characterized as low-fat and high-carbohydrate diets. A low-fat diet has beneficial effects for the prevention or treatment of diseases related to insulin resistant syndrome [2], however, several studies have reported that a traditional diet based on white rice may have adverse effects on obesity in Korean adults [3], Hispanic elders [4] and Japanese women aged 18 to 20 years [5]. 
Barley is a grain-based food, similar to white rice, but it has the potential to control cholesterol $[6,7]$, blood glucose [8], appetite and reduce energy intake $[9,10]$. $\beta$-glucan, viscous dietary fibres present in barley, creates gastric distension and delays gastric emptying [11]. It also promotes the release of appetite-related hormones and enhances the signalling of fullness [12]. It has been reported that bread or a beverage containing barley $\beta$-glucan concentrate powder reduces energy intake. However, it has not been elucidated whether rice type food containing grains of high $\beta$-glucan barley reduces energy intake.

The aim of this study, therefore, was to investigate the effect of BAR on appetite and energy intake.

\section{Materials and Methods}

Subjects Twenty-two healthy Japanese women were recruited for this study. Eligibility was determined through the following inclusion criteria: 1) age range of 30-49 y; 2) BMI $>22 \mathrm{~kg} / \mathrm{m}^{2}$ and $<25 \mathrm{~kg} / \mathrm{m}^{2}$; 3) not smokers; 4) not dieting to gain or lose weight; 5) not in athletic training; 6) not pregnant or breastfeeding; 7) not taking medications known to affect appetite; 8) regularly ate three meals per day; 9) had no food allergies or extreme dislikes for the foods in the test meals. Any subject with a tendency toward a diagnosable eating disorder (anorexia nervosa or bulimia) was also excluded: this was tested using the Eating Attitudes Test (EAT-26) [13, 14]. This study was conducted according to the guidelines laid down in the Declaration of Helsinki and all procedures involving human subjects were approved by the Oriental Ueno Medical Examination Centre. Written informed consent was obtained from all subjects.

Foods Two different kinds of rice were used: BAR (retort packed barley products) and WR. Retort packed barley product (Omugi Seikatsu, Omugi Gohan, Otsuka Pharmaceutical Co., Ltd., Tokyo, Japan), containing high $\beta$-glucan barley, combined with white rice was prepared by microwave cooking on $600 \mathrm{~W}$ for $2 \mathrm{~min}$. WR was boiled using a rice cooker for about $50 \mathrm{~min}$. BAR provided $5.3 \mathrm{~g}$ of dietary fibre, including $2.9 \mathrm{~g}$ of $\beta$-glucan per serving. WR didn't contain dietary fibre or $\beta$-glucan. The energy value of breakfast was $1,048 \mathrm{~kJ}$, which is about $15 \%$ of the estimated energy requirement for healthy Japanese women [15]. Omelette was garnished with BAR or WR to adjust the total energy value to $1,048 \mathrm{~kJ}$. Omelette (Kewpie Corporation, Japan) was prepared by microwave cooking on $500 \mathrm{~W}$ for $3 \mathrm{~min}$. Nutrient compositions and energy values of breakfast are presented in Table 1. Proteins, fats, carbohydrates, dietary fibre and energy content were measured using the Kjeldahl, acid disintegration, subtraction, enzymatic digestion and calculation methods, respectively at the Japan Food Research Laboratory, Tokyo, Japan. $\beta$-glucan amounts were determined using BetaGlucan Assay kits (Megazyme International Ireland Ltd.).
Table 1 Nutrient composition and energy value of BAR, WR and omelette

\begin{tabular}{lccc}
\hline & BAR & WR & Omelette \\
\hline Serving (g) & 150 & 147 & 42 \\
Proteins (g) & 5.1 & 3.4 & 3.5 \\
Fats (g) & 0.9 & 0.4 & 1.1 \\
Carbohydrates (g) & 42.9 & 48.1 & 4.0 \\
Dietary fibre (g) & 5.3 & - & - \\
$\beta$-glucans (g) & 2.9 & - & - \\
Energy content (kJ) & 879 & 879 & 169 \\
\hline
\end{tabular}

$B A R$ cooked white rice with $\beta$-glucan enriched barley, $W R$ white rice

The test meals, consisting of six dishes, were served for lunch and dinner. Lunch consisted of 1) vegetable sandwiches, 2) roast beef sandwiches, 3) spaghetti with ham and mushroom, 4) spaghetti with tomato sauce, 5) baked fish and scallops, or 6) roast pork with demi-glaze sauce. Dinner consisted of 1) bonito carpaccio, 2) steamed vegetables, 3) spaghetti with spinach and bacon, 4) spaghetti Bolognese, 5) sauté marlin or 6) sautéed chicken with wine vinegar sauce. The dishes were prepared on each test day by a local hotel restaurant and were served on different plates in amounts of two servings. The content of each plate was known in weight and energy value, and the partially consumed plate was weighed to calculate the energy intake using Exceleiyou (Version 6.0, KENPAKUSHA, Japan). Nutrient compositions and energy values per $100 \mathrm{~g}$ of each food are presented in Table 2.

Study Design The study was a randomized crossover design with two different kinds of rice matched for energy content. Taste, odour and firmness of the two kinds of test rice were almost the same and subjects were unaware of treatments, however the two kinds of test rice were of different colour. We conducted the study on two separate days with a 7-day washout period. The night before test day, subjects were instructed to consume a standardized dinner in the evening before $2,100 \mathrm{~h}$ and were then required to be fasting until they reached the hotel restaurant. Upon arrival on the test day, subjects recorded the VAS regarding their hunger, fullness, satiety and prospective food consumption [15, 16]. After completing the VAS questionnaire, subjects consumed $150 \mathrm{~g}$ of BAR and $42 \mathrm{~g}$ of omelette, or $147 \mathrm{~g}$ of WR and $42 \mathrm{~g}$ of omelette at $0900 \mathrm{~h}$. At 1,300 h, subjects were given lunch and at $1,700 \mathrm{~h}$, subjects were given dinner. Subjects had $15 \mathrm{~min}$ to consume the entire breakfast, $20 \mathrm{~min}$ to consume an ad libitum lunch and dinner until 'comfortable satisfaction' $[15,16]$. All subjects consumed foods within the allotted time. Subjects consumed all meals in a personal cubicle to deter conversation about the test meal and visualization of consumption. Subjects completed the VAS questionnaires regarding their hunger, fullness, satiety and prospective food consumption before 
Table 2 Nutrient composition and energy value of $100 \mathrm{~g}$ of foods and dishes consumed at the ad libitum test meal

\begin{tabular}{lrrrrr}
\hline Foods & $\begin{array}{l}\text { Proteins } \\
(\mathrm{g})\end{array}$ & $\begin{array}{l}\text { Fats } \\
(\mathrm{g})\end{array}$ & $\begin{array}{l}\text { Carbohydrates } \\
(\mathrm{g})\end{array}$ & $\begin{array}{l}\text { Dietary fibre } \\
(\mathrm{g})\end{array}$ & $\begin{array}{l}\text { Energy } \\
(\mathrm{kJ})\end{array}$ \\
\hline Lunch & & & & & \\
$\quad$ Vegetable sandwich & 10.0 & 13.1 & 21.1 & 1.3 & 1,022 \\
Roast beef sandwich & 9.4 & 12.5 & 19.4 & 1.2 & 962 \\
Spaghetti with ham and mushroom & 5.5 & 5.0 & 20.3 & 1.9 & 624 \\
Spaghetti with tomato sauce & 3.2 & 1.2 & 17.3 & 1.5 & 399 \\
Baked fish and scallop & 16.7 & 8.8 & 0.9 & 0.1 & 659 \\
Roast pork with demi-glaze sauce & 13.2 & 5.0 & 1.9 & 0.4 & 472 \\
Dinner & & & & & 597 \\
Bonito carpaccio & 19.3 & 4.8 & 5.1 & 0.4 & 399 \\
Steamed vegetable & 1.3 & 5.9 & 9.9 & 1.8 & 587 \\
Spaghetti with spinach and bacon & 5.0 & 3.4 & 19.9 & 1.5 & 494 \\
Spaghetti Bolognese & 4.7 & 2.5 & 17.9 & 1.2 & 451 \\
Saute Marlin & 11.8 & 3.5 & 4.5 & 0.4 & 462 \\
Sauteed chicken with wine vinegar sauce & 13.8 & 5.1 & 1.0 & 0.2 & \\
\hline
\end{tabular}

and after all three eating occasions: breakfast, lunch and dinner. Subjects remained in the hotel's waiting room for the duration of the study period on each test day. Between eating occasions, subjects were limited to sedentary activity, i.e. reading or watching $\mathrm{TV}$.

Statistical Analyses Statistical analyses were performed using SAS software, version 9.3 (SAS Institute, Cary, NC, USA). The primary outcome variables were the cumulative energy intake (lunch + dinner), and subjects' perception scores on hunger, fullness, satiety and prospective food consumption derived from the VAS scores recorded in subject questionnaires before and after each eating occasion. The secondary outcome variables were energy intakes at the lunch and dinner, and each of the VAS scores time points. Energy intakes were analyzed using an analysis of variance (ANOVA) model suited to a two-period, two-treatment, and two-sequence crossover design. Each of the VAS scores time points was analyzed using paired $t$-tests (2-tailed). Statistical significance was defined at $P<0.05$. All data are presented as means \pm standard deviation. We estimated that twenty subjects would provide $90 \%$ power to detect a difference of $808 \mathrm{~kJ}$ of the cumulative energy intake (lunch + dinner) between groups, assuming a standard deviation of $1,017 \mathrm{~kJ}$ [9].>

\section{Results and Discussion}

Subjects The subject flow is summarised in Fig. 1. Twentyone healthy Japanese women completed the study. The mean age was $41.9 \pm 4.6 \mathrm{y}$ and BMI was $23.3 \pm 0.7 \mathrm{~kg} / \mathrm{m}^{2}$. One subject was excluded because she was not able to eat the BAR in time.

Energy Intake and Evaluation of Appetite Score Energy intakes at lunch and dinner are shown in Fig. 2. Energy intakes at lunch were significantly lower after BAR consumption $(3,061 \pm 681 \mathrm{~kJ})$ compared with WR consumption $(3,280 \pm$ $617 \mathrm{~kJ})(P=0.035)$. Energy intakes at dinner did not differ significantly after the different breakfasts. The cumulative energy intakes (lunch + dinner) were significantly lower after BAR consumption $(4,963 \pm 1,209 \mathrm{~kJ})$ compared with WR consumption $(5,374 \pm 1,079 \mathrm{~kJ})(P=0.021)$.

The mean appetite scores of all subjects after consumption of BAR and WR are shown in Fig. 3. Hunger score was significantly lower after BAR consumption compared with WR consumption at $240 \mathrm{~min}(P=0.032)$. Fullness score was significantly higher after BAR consumption compared with WR consumption at $240 \mathrm{~min}(P=0.038)$. Satiety score was significantly higher after BAR consumption compared with WR consumption at $60 \mathrm{~min}$ and $480 \mathrm{~min}(P=0.041$ and 0.027 , respectively). Prospective food consumption score was significantly higher after BAR consumption compared with WR consumption at 0,180 and $240 \mathrm{~min}(P=0.042,0.013$ and 0.019 , respectively).

Data showed that BAR was able to increase fullness, and decrease hunger and prospective food consumption before lunch, compared to WR. Additionally, BAR was able to reduce energy intakes at the subsequent ad libitum lunch and the cumulative energy intake (lunch + dinner) after breakfast, compared to WR.

Our results are consistent with previous studies showing that barley $\beta$-glucan modulates appetite and energy intakes [9, 
Fig. 1 Flow diagram of enrolment, random assignment, withdrawals and follow-up of the study subjects. $B A R$ cooked white rice with $\beta$-glucan enriched barley, $W R$ white rice

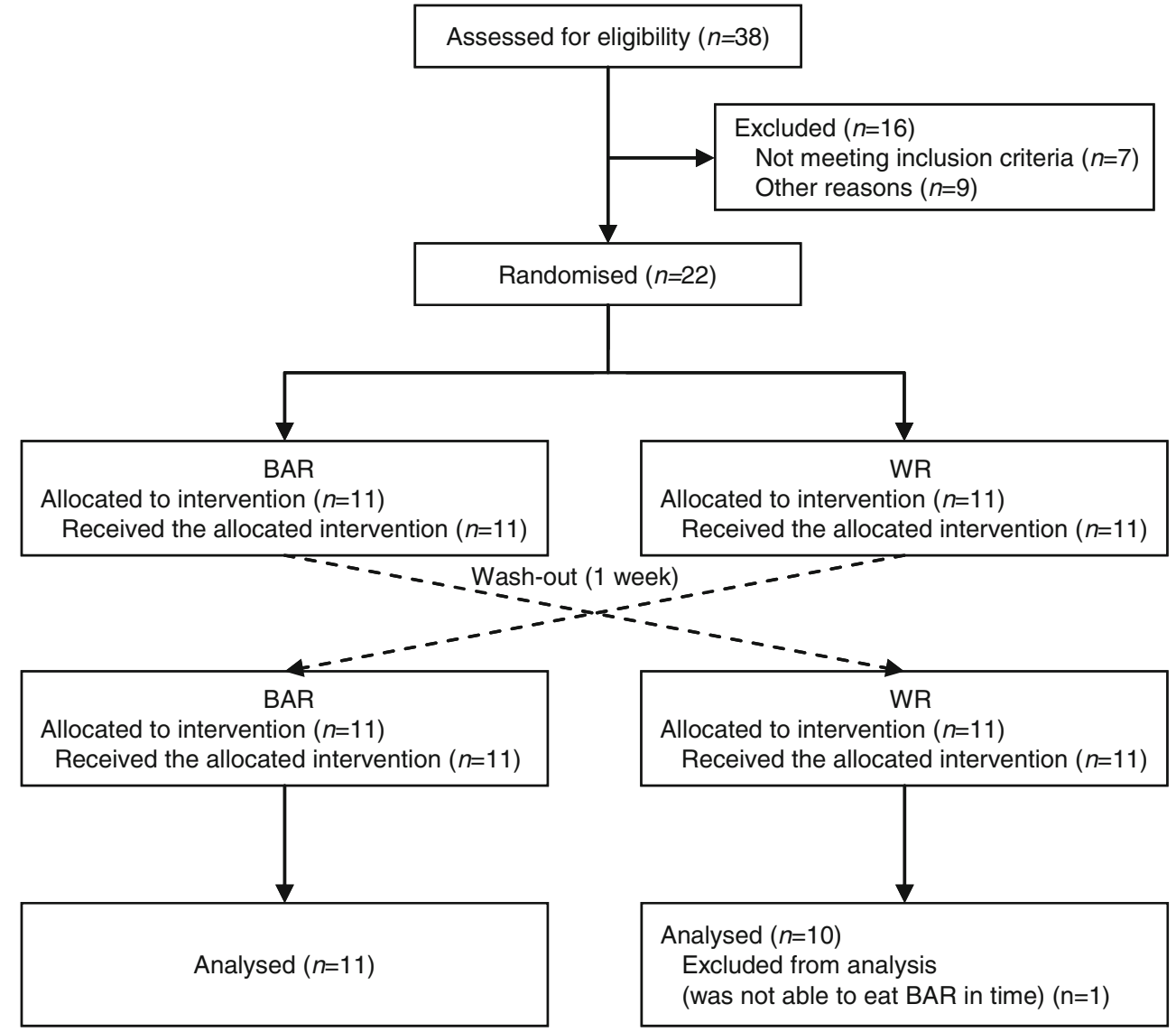

10]. Healthy subjects consuming a beverage containing barley $\beta$-glucan reported greater fullness and satiety over $3 \mathrm{~h}$ postbreakfast and reduced energy intake at lunch and over the rest of the day compared with fibre-free beverages [9].

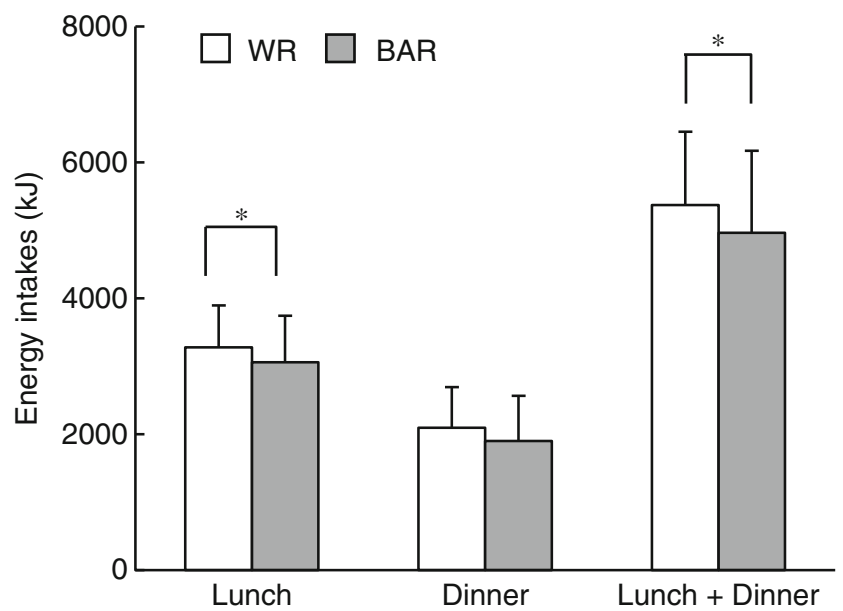

Fig. 2 Energy intakes (kJ) measured at ad libitum lunch and dinner, and the cumulative energy intake (lunch + dinner) subsequent to cooked white rice with $\beta$-glucan enriched barley $(B A R)$ or white rice $(W R)$ consumption. Values are means $(n=21)$, with their standard deviation. Energy intakes were analyzed using an ANOVA model suited to a two-period, two-treatment, and two-sequence crossover design. Statistical significance was defined at $* P<0.05$
Additionally, healthy subjects consuming $\beta$-glucan-enriched bread reported greater fullness and satiety, and reduced energy intake at a lunch meal compared with wheat bread [10]. In contrast, healthy subjects consuming barley $\beta$-glucanenriched biscuits reported greater fullness and satiety over $2 \mathrm{~h}$ post-breakfast following a midmorning snack compared with wheat biscuits, although ad libitum energy intake was not changed at lunch [17]. It has also been reported that consumption of barley bars containing $1.2 \mathrm{~g}$ of barley $\beta$-glucan did not change appetite and energy intake when compared with oat bars containing $0.3 \mathrm{~g}$ of oat $\beta$-glucan [18]. These studies have shown contradictory results on appetite and energy intake [9, $10,17,18]$ which may be due to differences in the amount and types of barley $\beta$-glucan used in each study.

Barley $\beta$-glucan may modulate appetite through various mechanisms: it has been found to delay gastric emptying and slow the glycemic response [19]. Barley $\beta$-glucan is thought to be hydrated in the stomach, and could thereby increase gastric distension. Gastric distension would lead to early satiation and is thus referred to as a volumetric response [20]. In our previous study, BAR was able to reduce the glycemic response and showed the second meal effect [21]. Since it was reported that the glycemic response is influenced by gastric emptying [19], delay of gastric emptying by BAR may be associated with mechanisms controlling appetite in our study. 

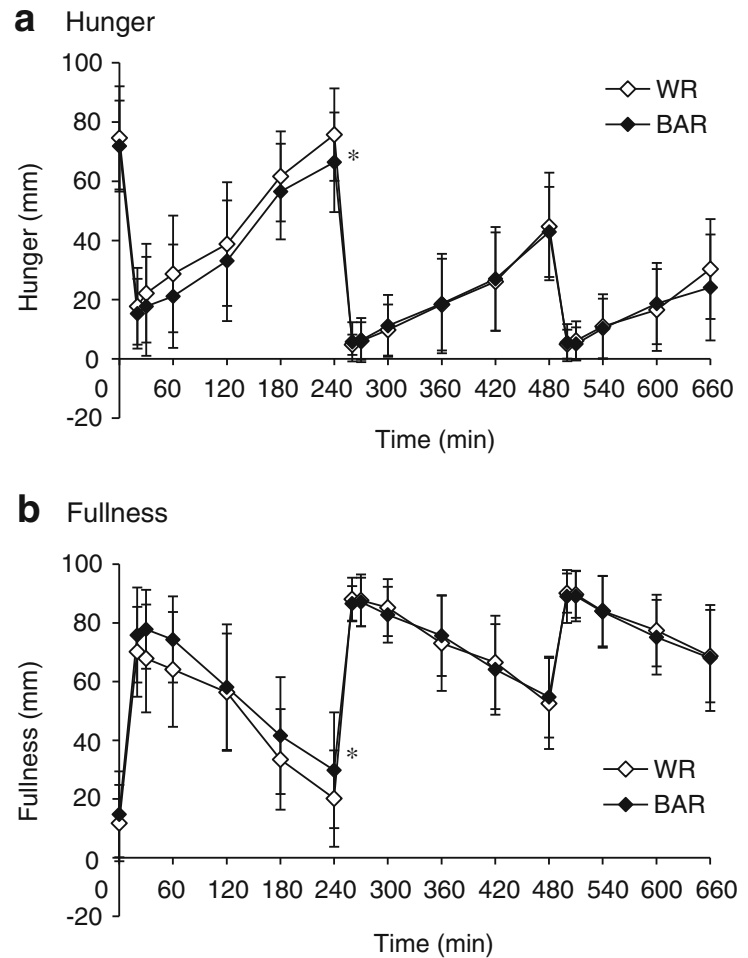

Fig. 3 The visual analogue scale $(V A S)$ scores of hunger, fullness, satiety, and prospective food consumption response after consumption of cooked white rice with $\beta$-glucan enriched barley $(B A R)$ and white rice $(W R)$. The line graph displays the time course of change throughout the testing day in the BAR $(\diamond)$ and WR $(\diamond)$ groups for VAS ratings of hunger, fullness,

In the current study, appetite was measured through subjects completing VAS questionnaires. Appetite may also be measured objectively by determining concentrations of appetite-related hormones, such as glucagon-like peptide-1(GLP-1), peptide YY(PYY), leptin, ghrelin, and cholecystokinin $[11,22]$. Barley $\beta$-glucan may influence the concentrations of circulating appetite-related hormones. Consumption of viscous and fermentable fibres has been shown to increase the secretion of appetiterelated hormones: pancreatic polypeptide, PYY, GLP-1 and ghrelin in humans $[9,10,23]$. The effects of barley on appetite-related hormones were not investigated in this study so we are unable to report their effect on appetite control in our study.

Others have proposed that short chain fatty acids produced during fermentation of dietary fibre in the colon may promote synthesis and secretion of GLP-1 [24]. In our previous study, we detected increasing breath hydrogen excretion in the $360 \mathrm{~min}$ after ingestion of BAR, which is reported to be a sign of colonic fermentation by intestinal bacteria. Since the control of appetite by BAR was seen before lunch, the results of this study may not be relative to colonic fermentation. Colonic fermentation may not to be related to the control of appetite by BAR because the rise in breath hydrogen excretion
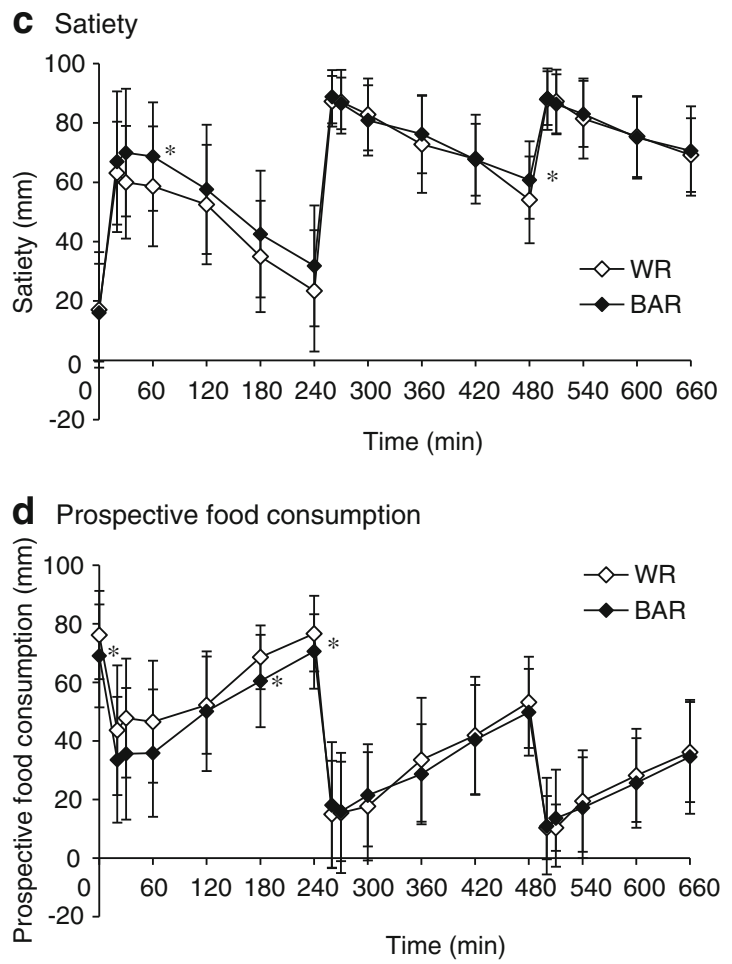

satiety and prospective food consumption at breakfast, lunch and dinner. Values are means $(n=21)$, with their standard deviation. Each of the VAS score time points were analyzed using paired $t$-tests (2-tailed). Statistical significance was defined at $* P<0.05$

was not seen before $240 \mathrm{~min}$ in our previous study (unpublished results) and another study [20].

There were several limitations to the present study. Participants were not blinded to the test rice that they received. It is possible that participants imagined the effect of the test rice on their appetite, and this may have affected appetite scores. However, participants were not informed of the feature of the test rice, therefore, participants were unlikely to have exhibited a socially desirable response bias. If such a bias was affecting results, it is expected that the difference in the VAS scores between treatments would have remained constant over time or perhaps be largest immediately after BAR ingestion.

Appetite-related hormone concentrations were not evaluated in our study because venesection might affect satiety and energy intake in some subjects: the presence of a cannula in the vein may produce a physiological effect [10]. In order to reveal the mechanism of BAR in modulating appetite and energy intakes, it is necessary to evaluate these hormone concentrations in another trial.

Adverse Events No adverse events related to the consumption of BAR were observed throughout the study according to the daily record and an interview with a doctor. 


\section{Conclusions}

This study showed that BAR was able to control appetite and reduce energy intake. The combination of white rice with high $\beta$-glucan barley could play a beneficial role in preventing and treating obesity and other obesity-related metabolic diseases.

Acknowledgments We thank Prof. Narumi Nagai (Department of Food Science and Nutrition, University of Hyogo) for her advice regarding the setting of study conditions. The present study was financially supported by Otsuka Pharmaceutical Co., Ltd., Japan.

Conflict of Interest None of the authors had a conflict of interest.

\section{References}

1. Abelson P, Kennedy D (2004) The obesity epidemic. Science 304: 1413

2. Bloomgarden ZT (2004) The 1st world congress on the insulin resistance syndrome. Diabetes Care 27:602-609

3. Kim J, Jo I, Joung H (2012) A rice-based traditional dietary pattern is associated with obesity in Korean adults. J Acad Nutr Diet 112:246253

4. Lin H, Bermudez OI, Tucker KL (2003) Dietary patterns of Hispanic elders are associated with acculturation and obesity. J Nutr 133: 3651-3657

5. Okubo H, Sasaki S, Murakami K, Kim MK, Takahashi Y, Hosoi Y, Itabashi M (2008) Freshmen in dietetic courses study II group. Three major dietary patterns are all independently related to the risk of obesity among 3760 Japanese women aged 18-20 years. Int J Obes (Lond) 32:541-549

6. Ikegami S, Tomita M, Honda S, Yamaguchi M, Mizukawa R, Suzuki Y, Ishii K, Ohsawa S, Kiyooka N, Higuchi M, Kobayashi S (1996) Effect of boiled barley-rice-feeding in hypercholesterolemic and normolipemic subjects. Plant Foods Hum Nutr 49(4):317-328

7. Shimizu C, Kihara M, Aoe S, Araki S, Ito K, Hayashi K, Watari J, Sakata Y, Ikegami S (2008) Effect of high beta-glucan barley on serum cholesterol concentrations and visceral fat area in Japanese men-a randomized, double-blinded, placebo-controlled trial. Plant Foods Hum Nutr 63(1):21-25

8. Rendell M, Vanderhoof J, Venn M, Shehan MA, Arndt E, Rao CS, Gill G, Newman RK, Newman CW (2005) Effect of a barley breakfast cereal on blood glucose and insulin response in normal and diabetic patients. Plant Foods Hum Nutr 60(2):63-67

9. Barone Lumaga R, Azzali D, Fogliano V, Scalfi L, Vitaglione P (2012) Sugar and dietary fiber composition influence, by different hormonal response, the satiating capacity of a fruit-based and a $\beta$ glucan-enriched beverage. Food Funct 3:67-75
10. Vitaglione P, Lumaga RB, Stanzione A, Scalfi L, Fogliano V (2009) beta-Glucan-enriched bread reduces energy intake and modifies plasma ghrelin and peptide YY concentrations in the short term. Appetite 53:338-344

11. Darwiche G, Björgell O, Almeŕ LO (2003) The addition of locust bean gum but not water delayed the gastric emptying rate of subjects. BMC Gastroenterol 3:12-19

12. Chaudhri OB, Salem V, Murphy KG, Bloom SR (2008) Gastrointestinal satiety signals. Annu Rev Physiol 70:239-255

13. Wells JE, Coope PA, Gabb DC, Pears RK (1985) The factor structure of the eating attitudes test with adolescent schoolgirls. Psychol Med 15:141-146

14. Mukai T, Crago M, Shisslak CM (1994) Eating attitudes and weight preoccupation among female high school students in Japan. J Child Psychol Psychiatry 35:677-688

15. Nagai N, Hibi M, Yamaguchi T, Kameo Y, Kobayashi S, Katashima M (2012) Development of the Japanese version of appetite sensations questionnaire using Visual Analogue Scales (VAS), and assessment of its reproducibility and validity. JJSSO 18:39-51

16. Flint A, Raben A, Blundell JE, Astrup A (2000) Reproducibility, power and validity of visual analogue scales in assessment of appetite sensations in single test meal studies. Int J Obes Relat Metab Disord 24:38-48

17. Vitaglione P, Lumaga RB, Montagnese C, Messia MC, Marconi E, Scalfi L (2010) Satiating effect of a barley beta-glucan-enriched snack. J Am Coll Nutr 29:113-121

18. Peters HP, Boers HM, Haddeman E, Melnikov SM, Qvyjt F (2009) No effect of added beta-glucan or of fructooligosaccharide on appetite or energy intake. Am J Clin Nutr 89:58-63

19. Thondre PS, Shafat A, Clegg ME (2013) Molecular weight of barley $\beta$-glucan influences energy expenditure, gastric emptying and glycaemic response in human subjects. Br J Nutr 110: 2173-2179

20. Powley TL, Phillips RJ (2004) Gastric satiation is volumetric, intestinal satiation is nutritive. Physiol Behav 82:69-74

21. Fukuhara I, Ikenaga T, Noguchi H, Kohashi C, Konagai S, Zembutsu K, Tomita S, Kohda N (2013) Effect of cooked rice with $\beta$-glucan enriched barley on postprandial glucose response and its second meal effect. Jpn Pharmacol Ther 41:789-795

22. Klok MD, Jakobsdottir S, Drent ML (2007) The role of leptin and ghrelin in the regulation of food intake and body weight in humans: a review. Obes Rev 8:21-34

23. Nilsson AC, Ostman EM, Holst JJ, Björck IM (2008) Including indigestible carbohydrates in the evening meal of healthy subjects improves glucose tolerance, lowers inflammatory markers, and increases satiety after a subsequent standardized breakfast. J Nutr 138: $732-739$

24. Massimino SP, McBurney MI, Field CJ, Thomson AB, Keelan M, Hayek MG, Sunvold GD (1998) Fermentable dietary fiber increases GLP-1 secretion and improves glucose homeostasis despite increased intestinal glucose transport capacity in healthy dogs. J Nutr 128: $1786-1793$ 